УДК 82I.I6I.I

ББК $83.3(2 \mathrm{Poc}=\mathrm{Pyc}) 4$
ЛЕТОПИСЕЦ НЕБЕСНЫХ ЗНАМЕНИЙ: ЛИЦЕВОЙ РУКОПИСНЫЙ СБОРНИК XVII ВЕКА ИЗ СОБРАНИЯ БИБЛИОТЕКИ РОССИЙСКОЙ АКАДЕМИИ НАУК: В 2 Т. Т.1: Факсимильное воспроизведение сборника. Т. 2: Тексты, исследование, комментарии / Изд. подгот. Г.В. Маркелов и А.В. Сиренов. СПб.: Изд-во Пушкинского Дома, 2018. 588 с.+528 с.: ил.

(C) 2020 г. Л.И. Сазонова

Институт мировой литературы

им. А.М. Горького Российской академии наук, Москва, Россия

Дата поступления статьи: І2 июля 2019 г. Дата публикации: 25 марта 2020 г.

DOI: Io.22455/2500-4247-2020-5-I-354-369

Аннотация: Названным академическим изданием в научный оборот вводится замечательный памятник русской литературы начала XVII в. - лицевой рукописный сборник энциклопедического содержания. Он включает единственный известный к нашему времени список «Летописца небесных знамений». Из разных историографических источников, летописей и хроник автор собрал воедино описания солнечных и лунных затмений, падений метеоритов, движений комет, явлений гало и северного сияния. Текст сопровождается рисунками астрономических и атмосферных явлений.

Ключевые слова: энциклопедический сборник, лицевая рукопись, летописец небесных знамений, солнечные и лунные затмения, падения метеоритов, явления гало и северные сияния, источники текста и изображений, текстология, палеография, кодикология, проблема авторства, рукопись-конволют, факсимиле, комментарий.

Информация об авторе: Лидия Ивановна Сазонова - доктор филологических наук, главный научный сотрудник, Институт мировой литературы им. А.М. Горького Российской академии наук, ул. Поварская, д. 25 а, І2Іо69 г. Москва, Россия.

E-mail: 1sazonova@mail.ru

Для цитирования: Сазонова Л.И. Летописец небесных знамений: Лицевой рукописный сборник XVII века из собрания Библиотеки Российской академии наук: в 2 т. Т. І. Факсимильное воспроизведение сборника. Т. 2. Тексты, исследование, комментарии / Изд. подгот. Г.В. Маркелов и А.В. Сиренов. СПб.: Изд-во Пушкинского Дома, 20I8. 588 с.+528 с.: ил. // Studia Litterarum. 2020. Т. 5, № I. C. 354-369. DOI: I0.22455/2500-4247-2020-5-I-354-369 


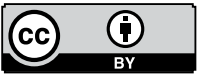

This is an open access article distributed under the Creative Commons Attribution 4.0 International (CC BY 4.0)

\section{THE CHRONICLE OF THE HEAVENLY SIGNS: 17TH CENTURY ILLUSTRATED HANDWRITTEN CODEX FROM THE COLLECTION OF THE LIBRARY OF THE RUSSIAN ACADEMY OF SCIENCES: IN 2 VOLS. Vol. 1: Facsimile Reproduction of the Collection. Vol. 2: Texts, Research, Comments. Ed. by G.V. Markelov and A.V. Sirenov. St. Petersburg, Publishing House of the Pushkinsky Dom, 2018.588 p. + 528 p.: il.}

(C) 2020. L.I. Sazonova

A.M. Gorky Institute of World Literature of the Russian Academy of Sciences, Moscow, Russia Received: July I2, 2019

Date of publication: March 25, 2020

Abstract: This article introduces a remarkable monument of the Russian literature - an illustrated manuscript collection of encyclopedic content, compiled at the beginning of the $\mathrm{I} 7^{\text {th }}$ century. It includes the only known list of The Chronicle of Heavenly Signs so far. An unknown author collected from various historical texts, chronicles and annals, descriptions of solar and lunar eclipses, meteorite falls and movements of comets, phenomena of halo and auroras. Along with the text, the manuscript contains drawings of astronomical and atmospheric events.

Keywords: encyclopedic collection, illustrated manuscript, chronicle of the heavenly signs, solar and lunar eclipses, meteorite falls, phenomenons of halo and auroras, text and image sources, textology, paleography, codicology, authorship problem, convolute manuscript,facsimile, commentary.

Information about the author: Lydia I. Sazonova, DSc in Philology, Director of Research, A.M. Gorky Institute of World Literature of the Russian Academy of Sciences, Povarskaya 25 a, I21069 Moscow, Russia.

E-mail: 1sazonova@mail.ru

For citation: Sazonova L.I. The Chronicle of the Heavenly Signs: $\mathrm{I}^{\text {th }}$ Century Illustrated Handwritten Codex from the Collection of the Library of the Russian Academy of Sciences: in 2 vols. Vol. I. Facsimile Reproduction of the Collection. Vol. 2. Texts, Research, Comments. Ed. by G.V. Markelov and A.V. Sirenov. St. Petersburg, Publishing House of the Pushkinsky Dom, 20I8. 588 p. +528 p.: il. Studia Litterarum, 2020, vol. 5, no I, pp. 354-369. (In Russ.) DOI: IO.22455/2500-4247-2020-5-I-354-369 
Фундаментальным изданием в научный оборот вводится замечательный памятник русской литературы начала XVII в. - лицевой рукописный сборник энциклопедического содержания. В период Смутного времени был составлен входящий в его состав интересный и не совсем обычный текст, сопровождаемый непонятными, на первый взгляд, схемами и чертежами: «Сия книга Летописец временем и знамением, яже на небеси и на земли» (далее - Летописец знамений). Неизвестный по имени автор свел воедино почерпнутые из различных историографических источников, русских летописей и западноевропейских хроник известия, содержащие рассказы о природных явлениях, необычных небесных знамениях: о солнечных и лунных затмениях, огненных столпах, полярных сияниях, падениях метеоритов, гало, паргелиях и др. Летописец не ограничился их описанием, но проявил интерес к условным изображениям астрономических и атмосферных явлений. В начале 2000-х гг. Г.В. Маркелов впервые обратил внимание на этот известный в единственном списке Летописец знамений как «на выдающийся памятник древнерусской книжности и уникальный комплекс изображений». В ряде публикаций исследователя рассмотрены различные аспекты изучения Летописца [2, с. 42-51; 3, с. 276-283; см. также: 4, с. 58-65; 5, с. 319-338].

Настоящее издание представляет собой всестороннее исследование рукописного сборника-конволюта, выполненное Г.В. Маркеловым и А.В. Сиреновым. Оно состоит из двух томов. В первом представлено полное факсимильное воспроизведение рукописного кодекса, хранящегося с середины XIX в. в Библиотеке Академии наук в собрании 
выдающегося ученого-слависта И.И. Срезневского ${ }^{\text {, }}$ собирателя ценных манускриптов.

Второй том содержит наборный текст сборника (с. 63-218), полистное описание его содержания (с. 219-232), именной, предметно-тематический и географический указатели к текстам рукописи (с. 233-248) и комментарии (с. 249-524). Предваряющая публикацию текста вводная часть («Предисловие», с. 7-62) включает палеографическое и кодикологическое описание рукописи, обзор ее содержания и рисунков (их сюжеты, графические композиции, техника исполнения, иконографическая традиция), установление источников текста, сведения об авторе-составителе сборника, историю бытования и изучения рукописи.

В отличие от высказанного ранее в научной литературе предположения о наличии в сборнике более 40 почерков, исследователи доказывают, что изучаемая рукопись написана рукой одного мастера-книжника. Факсимильное издание предоставляет читателю возможность удостовериться в правомерности приведенного суждения.

Для решения вопроса о личности автора-составителя, не названного в сборнике ни по имени, ни по роду своих занятий, Г.В. Маркелов и А.В. Сиренов проанализировали исторические обстоятельства, детали и подробности, почерпнутые из авторских приписок, косвенных данных изучаемого сборника, и выдвинули предположение о принадлежности автора-составителя к разряду иконописцев. Исследователи обратили внимание на явный интерес у составителя Летописца к живописным работам в казанских храмах, на особое внимание к цвету, на присутствие в тексте терминологии, используемой профессиональными иконописцами-знаменщиками, на статью о свойствах краски порфиры (пурпур). Описание внешнего облика трех святителей - Василия Великого, Григория Богослова, Иоанна Златоуста - содержит характеристики даже более детальные, чем в иконописных подлинниках. Исследователи выдвинули обоснованное предположение, что автор Летописца знамений «имел отношение к росписям Свияжского Успенского собора» (т. 2, с. 494). В составе сборника имеются материалы, посвященные иконографии, богословским толкованиям сложных иконописных композиций («О кресте Господни, что ради пишут у кре- 
ста Господня десную страну горе подножек Христов подоимашеся, а ошую доле понижшуся»; глава из полемического трактата Зиновия Отенского «Истины показания» о новонаписанных иконах, появившихся в конце XVI в.). Из приведенных наблюдений вырисовывается образ пребывающего в Казани книжника-иконописца. То, что рукописный кодекс был создан в Казани, подтверждается обилием разнообразных местных известий. Дополнительные штрихи к портрету автора Летописца знамений исследователи извлекают, изучая круг его источников и некоторые предпочтения, выразившиеся в привлечении западнорусских и западноевропейских известий, в некоторых речевых особенностях, связанных с употреблением в отдельных случаях западнославянской лексики, в упоминании западноевропейских топонимов и реалий. Автор-составитель сборника, сообщивший также некоторые сведения о своей семье, принадлежал, возможно, к белому духовенству Казани и был связан с Казанским архиерейским домом. Однако кто именно является этим автором - вопрос открытый.

Палеографическое и кодикологическое описание сборника-конволюта является базовой основой для датировки и реконструкции истории его создания. Изучение порядка следования в рукописи разновременных тетрадей, их соотнесенности с филигранями, содержанием статей и приписками позволило исследователям выявить восемь кодикологически единых блоков, что отражает довольно продолжительную историю формирования кодекса и одновременно целенаправленную работу составителя над его композицией. Не случайно на первом месте оказался текст из более позднего (по отношению к другим частям рукописи) книжного блока, датируемого 30-40-ми гг. XVII в., - связанное с новозаветными событиями синаксарное чтение Страстной пятницы. Поместив тем самым «события голгофской казни на первое место в сборнике, автор представил их как первые в христианской истории, прообразующие будущие знамения в последующей череде землетрясений, затмений солнца и других бедствий» (т. 2, с. 25I).

Летописец знамений помещен ниже, хотя он читается в более раннем кодикологическом блоке (состоит из девяти тетрадей: № 3-II), датируемом исследователями I605-I606 гг. на основании авторской правки в известиях о Лжедмитрии I - «ростриге Грише Отряпьеве». Возникает, однако, вопрос: как указанная дата создания данного памятника соотносится с тем, что сказано на 275-й странице издания: «...в I607 г. комету Галлея в небе 
над Московским государством наверняка видел и автор Летописца знамений. Возможно, это наблюдение впечатлило его и послужило дополнительным толчком (курсив мой. - Л.С.) к составлению Летописца знамений»? Из приведенной цитаты следует, что автор начал работу над Летописцем не ранее 1607 г.

Следует отметить, что датировка сборника-конволюта - сложная проблема. В 39 тетрадях рукописи выявлено 20 филиграней, не все из них удалось идентифицировать, что и ограничивает возможности точной датировки создания рукописного кодекса. Возможно, этим же обстоятельством объясняется непоследовательность хронологических указаний. Так, на первой странице «Предисловия» сборник отнесен к «первой половине XVII в.» (т. 2, с. 7). Далее исследователи уточняют: самые первые тексты относятся к I605 г., а последние к зо-м гг. XVII в.: «кодекс был сформирован не позднее 30-х гг.» (т. 2, с. 27); затем следует разъяснение: «Таким образом, сборник представляет собой творческий архив неизвестного нам по имени жителя Казани, содержащий материалы, создаваемые с начала XVII в. до зо-х г2. этого столетия. Таким образом, свой творческий архив автор пополнял на протяжении более чем трети века - можно думать, всю свою жизнь» (т. 2, c. 42-43). Раздел «Описание рукописи» открывается, однако, несколько иным утверждением: «Сборник энциклопедический, конволют. XVI 8. (конец) - XVII в. (30-40-е г2.)» (т. 2, с. 9; курсив мой. - Л.С.). Из сказанного следует, что если принять во внимание указанный хронологический диапазон, то автор, рукой которого написана вся рукопись, работал над составлением сборника даже не более «трети века», а более полувека (?).

Историко-культурное и историко-литературное значение данного кодекса определяется богатством его содержания и неповторимым художественным обликом. Из множества источников почерпнуты более 270 статей разного объема, представляющих собой многообразие жанров (повествовательных, полемических, учительных и др.), восходящих к разнообразным источникам. Известия из русской и мировой истории, чередующиеся со статьями из бестиариев, Шестоднева, Физиолога, Толковой Палеи, Христианской топографии Козьмы Индикоплова, Сказания об Индийском царстве и др., заимствуются или дословно, или пересказываются с сокращениями и излагаются в авторской редактуре составителя сборника. Летописец знамений имел своей целью фиксацию природных явлений, что объясняет 
склонность автора к описанию катастрофических событий (землетрясения, извержения вулканов, наводнения, смертоносные эпидемии, мор) и чудесных знамений. Примечательно, что, избрав лапидарную манеру изложения, книжник, сообщая о том или ином небесном знамении, устраняет мистическое толкование, сокращает морализаторскую часть, присутствующую в источнике; внимание нашего летописца занимает событие само по себе, что заметно отличает его от предшественников.

Особый интерес представляет в Летописце знамений комплекс собственно литературных произведений. Среди них - памятник древнерусской литературы XII в. Чудо Климента папы Римского о корсунском отроке и о перенесении мощей Климента Римского в Киев; поэтическое слово-плач по случаю кончины царя Федора Иоанновича, датируемое Смутным временем (второй известный список); новая редакция Повести об основании Ватопедского монастыря; переводные повести и сказания о богословах Евагрии и Оригене, о раскаявшемся в грехах и воскресшем воине Таксиоте; латинские по происхождению тексты о римских папах Мартиниане и Сильвестре, западнославянские сказания о чешской княгине Людмиле, о польском короле Болеславе и епископе Венцлаве; легенда о гусеногой сивилле Марии, предваряющая пространные сказания о двенадцати сивиллах.

Среди разнообразных материалов сведущий книжник поместил также сказание патриарха Геннадия о радуге, притчу о теле человеческом, сообщения о книжных собраниях царя Соломона, о древних собирателях книг Иезекии, Оригене, Исидоре Пилусийском и Птоломее-книголюбце, об эдемском рае и райских реках, о Моисее, о волхвах персидских, о кресте Христовом и др. Имеются выписки о «британских племенах», об Индии, о «земле Исляндии», о городах Аргентине (Страсбург) и греческих Дельфах, об индонезийском острове Суматра, о добывании драгоценных камней, о песчаных морях и о реке Рейн и др.

Составитель рукописи проявил традиционный для древнерусского книжника интерес к экзотике и курьезам, ко всяким удивительным случаям и чудесам, рассказам о монстрах, «дивиих людях, живущих на краю земли», о рождении свиньи с человеческим лицом и телят в виде сиамских близнецов, о саранче с греческими буквами на крыльях, о жительнице Кракова, родившей 36 детей, повествования о слепом псе кузнеца и псе, изобличившим убийцу 
своего хозяина, и др. В рукопись включены рассказы о баснословных и реальных животных: струфокамиле (страусе), инъроге (единороге), телчеслоне, вепреслоне, одонтотураноне, саламандре, ехидне, аспиде (крылатом змее), ноздророге (носороге), водяном коне (бегемоте), о птицах сирине, алконосте, фениксе, неясыти (пеликане) и др. Некоторые из представителей фауны преподносят читателю нравственный урок, указывающий путь к добродетели. Автор пишет, если воспользоваться его цитатой из статьи Максима Грека о птице струфокамиле, - «поучения для, а не красоты».

Есть в Летописце агиографические тексты - Житие Богоматери, приписываемое Епифанию Кипрскому, Житие мученика Христофора Песьеглавца; апокрифы - Житие Богородицы, о наречении имени Адама, об оживленной курице, о крашеных яйцах, о царе Семеклии и братстве его сына Прова со Христом.

Книжник-энциклопедист привлек при создании казанского кодекса чрезвычайно широкий круг самых разнообразных источников. В результате детального источниковедческого анализа Г.В. Маркелов и А.В. Сиренов установили, что этот удивительный сборник основан по преимуществу на историографических текстах - это Хронограф редакции I5I2 г., Московский Летописный свод конца XV в., Типографская, Никоновская летописи, близкая к Супрасльской белорусско-литовская летопись, Степенная книга, русский перевод Хроники Мартина Бельского. По предположению исследователей, привлекался также так называемый Лыткинский хронограф (начало XVII в.). Очевидный кирилло-белозерский «след» в изучаемой рукописи объясняется тем, что одним из основных источников Летописца знамений послужил «Летописец от 72 язык», список которого (Лихачевский) хранился в XVI в. в Кирилло-Белозерском монастыре; по всей вероятности, с его бывшим игуменом Матфеем, впоследствии казанским митрополитом, был знаком наш автор-составитель.

Есть в Летописце знамений уникальные сведения, которые не прослеживаются по другим источникам, они касаются в основном казанских событий: это сообщение о кончине и захоронении в Казани иерусалимского архиепископа Епифания и сооружение склепа на его могиле, описание голода в Казани в I6ог г., известия о росписи казанских церквей в I604 г., обстоятельствах убийства Богдана Бельского, о казанском юродивом Тимофее на рубеже XVI-XVII вв. 
Исследователи привели примеры, свидетельствующие о вероятном использовании автором также устных источников, например, в известиях о смерти Бориса Годунова, в сообщении о венчании на царство Лжедмитрия I и его прибытии в Москву. В том, что касается текстов литературного характера, рукописный компендиум казанского книжника унаследовал и продолжил традицию энциклопедических сборников Ефросина Белозерского (XV в.).

Полигистор-книжник предстает в этой рукописи и как опытный рисовальщик. Статьи Летописца знамений сопровождаются оригинальными изображениями, являющимися авторскими иллюстрациями к тексту (их около 70). Необычные контурные рисунки, выполненные легкими, быстрыми росчерками пера, без раскраски или слегка подцвеченные киноварью, являются органической частью самой рукописи, выступая как продолжение скорописной манеры письма. Изображения небесных явлений, которым автор придал антропоморфный вид, следуют словесному описанию комет, затмений солнца и луны, пятен на солнце, метеорных дождей, полярных сияний, огненных столпов, гало и паргелий, шаровой молнии в виде клубящегося огненного облака. Кроме небесных знамений, в сборнике помещены изображения животных и растений, го́рода с башнями и крепостными стенами, природных катаклизмов (вулканы, землетрясения).

Рисунками снабжены также повествовательные тексты. Сказание «О сивиллах мудрых», взятое из Хроники Мартина Бельского, проиллюстрировано весьма колоритными фигурами прорицательниц. Редкая повесть о святом архиепископе Венцлаве (Вениславе), убитом польским королем Болеславом, проиллюстрирована шестью картинками. В некоторых случаях оставлены свободные места для иллюстраций между текстами или внутри нарисованных рамок, однако по какой-то причине так и незаполненные. Исходя из содержания рукописи, исследователи привели перечень несостоявшихся рисунков. Если бы художественный замысел книжника реализовался в полной мере, то перед нами предстала бы самая обширная подборка светских изображений начала XVII в.

Уровень текстологической подготовки кодекса отвечает необходимым требованиям. Редакторская работа самого книжника отражена в подстрочных примечаниях, где отмечены вставки слов и приписки текста (над строкой или на поле рукописи), зачеркивания, изменение синтаксического порядка, лексические замены, смена чернил и др. 
Развернутый научный комментарий к тексту рукописи составляет более половины объема второго тома. Каждая статья сборника рассматривается в последовательности ее расположения в кодексе; приводятся разного рода сведения, относящиеся к историко-культурному контексту, источники текста и параллели к нему, объяснения отдельных понятий и исторических реалий, ценный изобразительный материал.

Комментарий включает более 500 изображений. Рисунки Летописца знамений помещены в контекст иконографической традиции XIII-XVIII вв., им находятся источники или предполагаемые образцы в древнерусской и русской рукописной книжности, в западноевропейских изданиях. Разыскания Г.В. Маркелова и А.В. Сиренова привели к выводу о том, что толчком к созданию рисунков Летописца знамений могли послужить изображения из упомянутого царского Лицевого свода XVI в. Твердо установлено, что автор сборника мог воспользоваться также гравюрами из Хроники Мартина Бельского, из перевода которой в Летописец знамений вошло немало статей. Убедительно показано, что одним из источников рисунков для летописного сборника стали гравюры из изданий немецких хроник Гартмана Шеделя и Конрада Ликостена (переведена в Москве в I599 г.): очевидное сходство наблюдается в графических композициях, в применении штриховки как светомоделирующего приема. В ряду предполагаемых источников находятся изображения небесных явлений на немецких гравированных листах XVI в. Рисуя животных, автор Летописца ориентировался на иконографию лицевых списков Физиолога и Козьмы Индикоплова. В составе Летописца знамений до нас дошла самая ранняя миниатюра к тексту Хождения Трифона Коробейникова - фараонова рыба Понтийского моря. Автор Летописца проявил себя как рисовальщик, представивший оригинальные композиционные решения (сцена извержения Везувия; совершенно уникальный рисунок с изображением копыт как иллюстрация к рассказу о скачущих бесах-всадниках).

Представлена и изучена художественная образность, в которой выражались взгляды людей на природу. В средневековых текстах падение метеоритов сравнивается с огненным змием. И на первом же рисунке в Летописце знамений падение метеорита при сыне Ярослава Мудрого, князе Всеволоде (XI в.), изображено в виде крылатого змея, спускающегося из облаков. Смотрящий вверх князь заслоняется правой рукой от пугающего 
зрелища. Знамению ужаснулись и другие очевидцы события так же, как это можно видеть на миниатюре из Радзивиловской летописи. Древнерусское искусство и западноевропейское того же времени знает немало изображений крылатых змиев. Исследователи привели ряд параллелей, свидетельствующих о том, что изображение змия в Летописце знамений выполнено вполне традиционно в рамках канона. На миниатюре к Троянской истории в составе Лицевого свода XVI в. крылатый змий с двумя лапами и извивающимся хвостом изрыгает пламя. Изображение летящего змея находим в сцене штурма Казани из лицевой рукописи Казанской истории. Крылатый змий-дракон присутствует и на гравюре из Хроники Ликостена.

Примечательно заимствованное из Московского свода XV в. описание солнечного затмения I мая II85 г., знаменитого тем, что оно отразилось и в «Слове о полку Игореве». В Летописце знамений текст не имеет морализирующей концовки, а сопровождающий его рисунок изображает ущербное солнце в виде месяца, «из рог» которого исходят пламенеющие лучи. По свидетельству астронома Д.О. Святского, на территории южной Руси затмение было частичным [7, с. 45-49], как свидетельствует о том и Ипатьевская летопись. Однако в «Слове о полку Игореве» оно представлено как полное: «Солнце ему тъмою путь заступаше...». Заметим, что «неточность» описания объясняется художественной природой произведения: изображение затмения именно как полного способно создать глубокий и емкий символический образ, служащий грозным предзнаменованием неудачи военного похода князя Игоря.

Явление кометы в рисунках Летописца знамений изображено в виде наконечника копья, как и в Лицевом своде XVI в. В западноевропейских гравюрах того же времени и в русских источниках («Тобольский летописец», XVIII в.) встречается и другой тип изображения - в виде падающей звезды с хвостом. Любопытна запись Симеона Полоцкого, сделанная им в Москве о комете г664 г. (комета была открыта 7/г7 ноября г664 г. и наблюдалась до января І665 г.). В ней не просто зафиксировано явление кометы, но и сообщаются также астрономические наблюдения о направленности хвоста: «Tegoż roku y miesiąca dnia szóstego pokazała sie cometa, trwała niedziel z pultoru y zgasła potym zaś w dzień aż do Kreszczenia Hospodnia. Ogoń miał na pułnoc, potym na wschód ku południewi»² («Того же года и месяца в 
шестой день появилась комета, она держалась недели полторы, потом погасла в день накануне Крещения Господня. Хвост имела [направленный] на юг, потом на юго-восток»).

В дневниковой записи Симеона описание кометы свободно от морализации, в отличие от стихотворения Евфимия Чудовского о комете I680 г. «На звезду великую, явльшуюся І89 году декабря против I5-го числа»3 ${ }^{3}$ Известно, что эта комета была очень яркой, в некоторые дни ее хвост («труба», «столп») достигал большой величины (до 7о градусов в длину), что отмечено многими очевидцами и в России, и в Западной Европе, оставившими описание и зарисовки «великой звезды». Комета была открыта 4/І4 ноября г68о г. и наблюдалась до марта г68г г., в середине декабря ее блеск заметно усилился, и именно к моменту наибольшего свечения кометы относится большинство свидетельств о ней [6, с. 350-353; I, с. 43]. Среди литературных произведений - и стихотворение Евфимия. Он признает влияние кометы на жизнь людей как проявление божественной воли и воспринимает небесное явление как недоброе предзнаменование, не сулящее никакого «блага», но предвозвещающее «гнев Божий и казнь людем»: «Комита егда в небе видена бывает, / никое благо быти на земли являет,

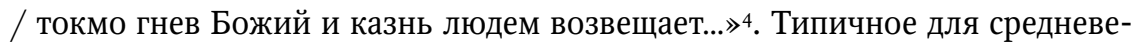
кового сознания представление соединилось в стихотворении с дидактической интерпретацией, внушающей мысль о возможности преодолеть неотвратимость кары Божией добрыми делами: автор призывает «ущедрить» Бога «благодеяниями» и избегать «неправд всяких и обид», тогда «показанный нам знак на многое злое / превратит Всеблагий Сый на всяко благое, / токмо покажем делы покорство драгое»5.

Стихотворение Евфимия находится в традиции астрономическоастрологических сочинений, столь характерных для его эпохи. Внимание к небесным знамениям, сопутствовавшее всему Средневековью, приобрело в России во второй половине XVII в. характер моды, распространившейся в высшем феодальном обществе, как светском, так и церковном; известно о прогностической астрологии на «службе» у царя Алексея Михайловича [8, c. 85-II4].

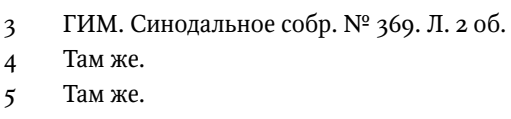


Комментарий к легенде «О сивиллах мудрых» включает изображения 15 пророчиц из Летописца знамений - эти старейшие в русской рукописной традиции рисунки ранее были не известны исследователям. Они приведены в сравнительном анализе с изображениями сивилл в росписи Благовещенского собора, в миниатюрах из рукописи рубежа XVI-XVII вв. РНБ. ОЛДП. Q. 795, в Хронике Бельского и в Хронике Шеделя. При дальнейшем изучении иконографической традиции изображения сивилл можно учесть также лицевую рукопись («Книга о сивиллах», I673) рах которой образы пророчиц выполнены в традиции западноевропейской портретной живописи.

Изображение птицы феникс из Хроники Ликостена представлено в комментарии к листу 215 об. - 216 (с. 497), поэтому ссылка (на с. 420) на комментарий к листу 66 ошибочна. Имеются пропуски в указателях: например, в именном отсутствуют «Гриша (Грища) Отряпьев» (Лжедмитрий I), сивиллы Кумана, Хелеспонская, Европия, в географическом - название города Лянферберг, в предметно-тематическом - сивиллы, радуга, притча о теле человеческом и др.

Богато иллюстрированный (лицевой) кодекс - явление в рукописной традиции исключительно редкое и чрезвычайно ценное. Данной публикацией пополнился немногочисленный ряд факсимильных изданий летописных памятников русского Средневековья и раннего Нового времени (Радзивиловская летопись, XIII в.; Лицевой летописный свод XVI в.; Ремезовская летопись, конец XVII - начало XVIII вв.).

Лицевой летописный кодекс из собрания И.И. Срезневского - замечательный памятник своей эпохи. Его публикация открывает перспективы для открытия личности автора и для дальнейшего осмысления историко-литературных и историко-культурных процессов, происходящих в России на пороге раннего Нового времени. Это научное издание выполнено на высоком профессиональном уровне. Вместе с тем комментарии, включающие богатый иллюстративный материал, делают его привлекательным и доступным для широкого круга читателей, интересующихся историей русской культуры.

Остается добавить, что двухтомное издание «Летописца небесных знамений» вышло под грифом трех научных учреждений: Институт русской 
литературы (Пушкинский Дом) РАН, Санкт-Петербургский институт истории и Библиотека Российской академии наук. Прекрасно оформленное, одно из лучших, выпущенных издательством Пушкинского Дома, оно опубликовано благодаря финансовой поддержке председателя Федерального Совета ВПП «Партия Дела», президента ООО «Новое Содружество» и ассоциации «Росспецмаш» К.А. Бабкина. 


\section{Список литературы}

I Воронцов-Вельяминов Б.А. Очерки истории астрономии в России. М.: Гостехиздат, I956. $397 \mathrm{C}$.

2 Маркелов Г.В. «Явися на небеси знамение чюдно» // О древней и новой литературе: сб. ст. в честь Н.С. Демковой. СПб.: Филологический факультет СПбГУ, 2005. C. 42-5I.

3 Маркелов Г.В. О «Летописце небесных знамений», летописном памятнике начала XVII в. // Пятые Лихачевские чтения. Русская культура: история и экология. Материалы междунар. науч. конф. Ясная Поляна, 20І6. С. 276-283.

4 Маркелов Г.В., Сиренов А.В. О личности автора «Летописца о небесных знамениях» // Русская литература. 20I6. № 2. С. 58-65.

5 Маркелов Г.В., Сиренов А.В. Иконография лицевого Летописца о небесных знамениях // Вестник СПбГУ. История. 20І7. Т. 62. Вып. 2. С. 319-338.

6 Святский Д.О. Комета г680 г. в России // Мироведение. г929. № 6. С. 350-353.

7 Святский Д.О. Астрономия в Древней Руси. М.: Русская панорама, 2007. 664 с.

8 Симонов Р.А. Русская астрологическая книжность (XI - первая четверть XVIII века). М.: Мир книги, I998. I47 с. 


\section{References}

I Vorontsov-Vel'iaminov B.A. Ocherki istorii astronomii v Rossii [Essays on the History of Astronomy in Russia]. Moscow, Gostehizdat Publ., I956. 397 p. (In Russ.)

2 Markelov G.V. "Iavisia na nebesi znamenie chiudno" [A Miraculous Sign Appeared in the Sky]. O drevnei i novoi literature: Sb. st. v chest' N.S. Demkovoi [On the Ancient and New Literature. Collection of Articles in Honor of N.S. Demkova]. St. Petersburg, Filologicheskii fakul'tet SPbGU Publ., 2005, pp. 42-5I. (In Russ.)

3 Markelov G.V. O “Letopistse nebesnykh znamenii”, letopisnom pamiatnike nachala XVII v. [On “The Chronicler of the Heavenly Signs”, a Chronicle Monument of the Early $7^{\text {th }}$ Century]. Piatye Likhachevskie chteniia. Russkaia kul'tura: istoriia i ekologiia. Materialy mezhdunarodnoi nauchnoi konferentsii [The Fifth Lihachev Readings. Russian Culture: History and Ecology. Materials of the International Scientific Conference]. Yasnaya Polyana, 20I6, pp. 276-283. (In Russ.)

4 Markelov G.V., Sirenov A.V. O lichnosti avtora "Letopistsa o nebesnykh znameniiakh" [On the Identity of the Author of "The Chronicler of the Heavenly Signs"]. Russkaia literatura, 20I6, no 2, pp. 58-65. (In Russ.)

5 Markelov G.V., Sirenov A.V. Ikonografiia litsevogo Letopistsa o nebesnykh znameniiakh [The Iconography of the Illustrated "Chronicler of the Heavenly Signs"]. Vestnik SPbGU. Istoriia, 2017, no 62 (2), pp. 319-338. (In Russ.)

6 Sviatskii D.O. Kometa I680 g. v Rossii [The Comet of I680 in Russia]. Mirovedenie, I929, no 6, pp. 350-353. (In Russ.)

7 Sviatskii D.O. Astronomiia v Drevnei Rusi [Astronomy in the Ancient Russia]. Moscow, Russkaia panorama Publ., 2007. 664 p. (In Russ.)

8 Simonov R.A. Russkaia astrologicheskaia knizhnost' (XI - pervaia chetvert' XVIII veka) [Russian Astrological Booklore ( $\mathrm{II}^{\text {th }}-$ the first Quarter of the $\mathrm{I} 8^{\text {th }}$ Century)]. Moscow, Mir knigi Publ., I998. I47 p. (In Russ.) 